\title{
Engaging Families via the Internet: Process and Challenges
}

\author{
Laurie A. Bulock ${ }^{1}$, Barbara D. Ames, Jodi Spicer, \\ and David R. Imig
}

\begin{abstract}
A number of questions evolve around the best mechanism for using technology to support families and give voice to their special needs and interests across the life course. This article describes the processes and challenges involved in developing a longitudinal online data collection system and building an online community. While research is beginning to emerge which describes how families use the Internet for knowledge acquisition, this project is unique in its attempt to engage families as producers and consumers of knowledge, in addition to being partners in the process of developing an online community.

${ }^{1}$ Laurie Bulock is a doctoral student in the Department of Family and Child Ecology, Michigan State University, East Lansing, MI 48824. Electronic mail may be sent to bulockla@msu.edu
\end{abstract}

Key Words: Families and technology, online communities, family resilience, collaborative research

A number of questions evolve around the best mechanism for using technology to support families and give voice to their special needs and interests across the life course. In this article we describe the processes involved in developing a longitudinal online data collection system and building an online community namely, the Connecting Michigan Families Program. This project is a collaborative effort among families in thirteen Michigan counties, Michigan State University Extension and county Extension professionals, and MSU faculty and students. We emphasize the processes and lessons learned in engaging families and county Extension educators in a shared vision of the value of 
sustained online data collection and online exchanges of family knowledge and experiences. We also address the challenges and successes of such a collaborative effort, as well as implications for research and practice. There are many unanswered questions about the role of the Internet in a) family resource management and decision-making; b) the interactions between family and social capital; and c) enhancing family resilience processes. While research is beginning to emerge which describes how families use the Internet for knowledge acquisition, this study is unique in its attempt to engage families as producers and consumers of knowledge, in addition to being partners in the process of developing an online community.

\section{Project Summary}

The project summary is divided into two sections. The first section provides a brief description of the project in its early stages - Phase I. The second section describes Phases II and III.

\section{Phase I: Connecting Michigan Families Program}

The purpose of the Connecting Michigan Families Program (CMFP) was to study the formation of social capital inherent in the development of an Internet-based community of families, local practitioners, and campus collaborators. The premise of this online community was to provide an opportunity for Michigan families to voice their interests and concerns, and to be heard by other families, community stakeholders and state decision-makers. Survey topics were created by input from families, and survey questions were phrased to provide insight into the issue of family resilience.

Focus groups were conducted during Phase I in three Michigan counties in order to build trust, determine needs relevant to Michigan families, determine resources and barriers that could affect project participation, and to generate participant-driven 
topics for online surveys. County Extension educators worked directly with families to build rapport, establish buy-in, and maintain communication and feedback loops. They also assisted families with technological issues. During this phase, two pilot online surveys were conducted on topics determined during the initial focus groups.

Lessons learned and feedback from families involved in Phase I informed the development of Phases II and III. Families indicated that a) they valued having a voice and sharing with other families; b) they wanted a more interactive website with instant access to survey results; and c) they wanted opportunities to interact online with other families and university experts on family issues.

Though Phases II and III are distinctly different and are described separately, it is important to note that they are being developed simultaneously in order to complement the process of engaging families. While engaging families has remained a key priority in the project's development, it was apparent in Phases II and III that engagement with Extension educators was equally important, and required a unique approach.

\section{Phase II: Family Resilience Study}

The purpose of the Family Resilience Study is to determine whether and how engagement in the development of an online community will enhance family resilience processes. A discussion of the conceptual framework is presented first, followed by a brief discussion of related literature and a description of the family resilience study.

\section{Conceptual Framework}

Elements of both family resilience and social exchange theory have informed this project. 
Engaging Families via the Internet 8

\section{Family Resilience}

Several models for the study of family resilience have emerged in the literature (Patterson, 2002; Olson, 1993; and McCubbin \& Patterson, 1983). For this study, Patterson's Family Adjustment and Adaptation Response (FAAR) Model (2002) is the most fitting in that it emphasizes the mechanisms by which families' meaning making processes (perceptions) balance family demands with family capabilities to achieve a level of adjustment. Family capabilities include tapping into new and existing resources that are internal to the family, as well as those found externally in the community. Using the FAAR Model, this project explores the potential influence that engagement in an online community might have on family resilience processes. Specifically, the project examines relationships among family strengths, challenges, perceptions, and resources. A strength of the study lies in the potential to follow families experiencing varying degrees of stress across time. Research, practice, and policy can be informed by lessons learned about family needs for promoting resilience, as well as lessons gleaned from the formation of social capital which results from the interactive nature of an online longitudinal engagement study.

\section{Social Exchange Theory}

While understanding resilience processes is the main focus of the Family Resilience Study, it is also important to gain an understanding of the motivations that would lead family members, and those working with families, to become engaged in the building of an online community. The social exchange framework is appropriate for this discussion because cost-reward ratios are often motivating factors for choosing to engage in a new activity (White \& Klein, 2002). Busy family members need to know why they should spend their time and share ideas with program staff and participants. At the same time, Extension educators in local 
counties need to know why they should expend energies working with families in a new way and working collaboratively with unfamiliar people on the university campus.

\section{Related Literature}

Few studies have been conducted that examine the dynamics involved with the development of new collaboratives using relatively new technologies. However there are some that can shed light on the motivations of family members to use interactive online resources. For instance, Barrera, Glasgow, McKay, Boles, \& Fei (2002) found that participants in an online social support group experienced greater increases in perceived social support for managing chronic diabetes compared to participants in groups that received either information only, a personal coach only, or a combination of information, personal coach and online social support. Similarly, Campbell, Meier, Carr, Enga, James, \& Reedy, et al. (2001) conducted a qualitative study which compared findings from face-to-face focus groups with findings from on-line chat focus groups among 12 individuals affected by colon cancer. Though findings were similar between groups in that study, on-line participants generally talked more about cancer treatment and advocacy issues and used support groups more frequently. While face-to-face participants drew support from family, the on-line participants drew support from more resources, such as family, face-to-face support groups, and on-line information resources and support groups. In addition to gaining access to more resources, participants in the online interactions in both studies expressed that the anonymity offered by the on-line interactions was important for discussing sensitive issues. Thus, participants who engaged in the online interactions experienced greater rewards than costs. According to both studies, costs associated with online participation included the need to type in order to participate, and possible shortening of discussions that otherwise might have flowed freely in face-to-face groups. 
Engaging local county Extension educators presents a different kind of challenge for building an online community with families. In such a collaborative effort, not only are educators asked to work with families in a new and uncharted way, but in an era of budget cuts, downsizing, and program-focused funding, they are faced with a possibility that using Internet technology to work with families may make their current jobs obsolete. Therefore, engaging these valuable family professionals requires casting an expanded vision for their roles such that the potential rewards exceed the perceived costs of their involvement. Smith (1999) suggested that family practitioners should consider themselves as coaches, rather than experts, to help families manage the amount and quality of information, as well as to coach families in applying that information to family needs. $\mathrm{He}$ also suggested that practitioners should be "constantly reinventing what they do as a necessary part of their professional work" (p. 33). On the other hand, choosing not to engage in using Internet technology could become a cost to practitioners. According to Smith, information is now a "commodity in a consumer-driven market" (p. 31). That is, consumers now have control over how, when, and where they access information. Practitioners who choose not to add Internet technology to their repertoire of strategies for working with families may create costs for themselves and miss the opportunity for new and exciting rewards. However, there is a lack of research that documents the processes involved with casting a vision and making clear the rewards involved with building an online community.

Although there is a dearth of research regarding the creation of on-line communities, the Pew Internet and American Life Project provides some insight into the use of the Internet by families. For example, in 2005, 24\% of rural Americans had highspeed connections at home, up from 9\% in 2003. This compares with $39 \%$ of families living in suburban and urban areas (Horrigan $\&$ Murray, 2006). Even though more adults are using the Internet, different access speeds create a new divide among internet users. 
Internet speed is a more important factor in Internet use than experience (Fox, 2005). In a 2003 regional comparison, 56\% of Michigan (as part of the Industrial Midwest also including Illinois, Indiana and Ohio) adults had Internet access (Spooner, 2003). This compares with a high of $68 \%$ in the Pacific Northwest and a low of $48 \%$ in the South. Finally, how men and women use the Internet has implications for delivering family life education and creating on-line communities. Men use the internet for the experiences it offers, while women use it to seek human connections (Fallows, 2005).

\section{Description of the Family Resilience Study}

In order to initiate the second phase, two of the original counties re-engaged as many of the core set of families from Phase I as possible and recruited more families for this quasiexperimental design. In addition, the project expanded to include families and Extension partners from 11 additional counties in Michigan. These expansion counties were recruited by county Extension personnel from the original two counties, and by a program leader from the campus Extension office.

Table 1. Description of Activities for Each Group

\begin{tabular}{|c|c|c|}
\hline Focus Group & Experimental Group & Control Group \\
\hline $\begin{array}{l}\text { - Participate in pre } \\
\text { and post focus } \\
\text { groups. } \\
\text { - Complete pre and } \\
\text { post demographic } \\
\text { survey and } \\
\text { depression and } \\
\text { mastery scales. } \\
\text { - Participate in } \\
\text { experimental group. }\end{array}$ & $\begin{array}{l}\text { Complete pre and } \\
\text { post demographic } \\
\text { survey and } \\
\text { depression and } \\
\text { mastery scales. } \\
\text { - Complete six } \\
\text { monthly online } \\
\text { surveys. } \\
\text { - Participate in the } \\
\text { online community } \\
\text { discussion forums. }\end{array}$ & $\begin{array}{l}\text { - Complete pre and } \\
\text { post demographic } \\
\text { survey and } \\
\text { depression and } \\
\text { mastery scales. }\end{array}$ \\
\hline
\end{tabular}


Each county conducted pre-test focus groups, similar to those conducted in Phase I, with the goal of engaging families, creating buy-in and generating participant-driven survey topics. In addition, each county recruited participants for experimental and control groups. In most counties, families that participated in the focus groups also enrolled in the experimental groups. Table 1 describes the activities in which those involved in the project participate, dependent upon the group in which they were placed.

Participants' active involvement in the online discussion forum includes posting questions, interacting with other families, or posting a family story. Active participation in all facets of the website is important to the continual improvement of technological and communication gaps, and strengthens our collaborative research model. After six months, participants from the pre-test focus groups will participate in post-test focus groups in order to debrief and provide feedback on the processes and subjective outcomes of their involvement. This information will inform further development of the Connecting Michigan Families Program. Table 2 summarizes the three phases and unfolding processes of building the Connecting Michigan Families Program.

\section{Phase III: Connecting Michigan Families Website}

The concept of a University-community based online community with families emerged from the feedback and processes of Phase I as described previously. The premise behind the online community is that the interactive capacity of the Internet can be tapped in order to maximize the potential for families and communities to involve themselves as producers of information as well as consumers. In turn, practitioners, stakeholders and policymakers would become consumers of information provided by families that would have relevance to their decision-making, programming, and priorities. They would have an opportunity to tap into the wisdom and experiences of their constituent families, and potentially to engage in online dialogue with them. In 
addition, there is the potential to gain insight concerning family resource management and decision making, family resilience, and the development of social capital inherent in the development of an Internet-based survey system. For Extension offices there is the potential to develop systematic family needs assessments in counties. For researchers and stakeholders there is the potential for policy analysis at the local, county and state levels.

The website address for the Connecting Michigan Families Program is http://mifamilies.msu.edu. Two facets of the website became operational during the summer of 2005, in time for the first participant families to complete online surveys and participate in the discussion board areas. The Family Resource Library, described below, is being developed as a collaborative effort with Michigan State University Extension professionals, and MSU faculty and students. The Connecting Michigan Families website contains the following components:

- The Family Learning Center houses the discussion forums. It is a place where families can have discussions with other families, pose questions, read responses to frequently asked questions, and share and read family stories.

- The Pulse of Michigan Families houses the option for survey topics identified by participating families. Families can complete the current survey and view the aggregate responses of other families for current and past surveys. They also can suggest topics for future surveys. Surveys completed to date include the topics of parenting, health care, and work-life issues.

- The Family Resource Library is a place where families can access information about family issues. Articles, papers, audio and video files, and web links to other sites will be available. This is a long term project that will always be "under construction." with families and communities as builders. 


\section{Challenges}

The challenges of developing a collaborative online community such as Connecting Michigan Families can be divided into three major categories. The first, and in many ways the most easily "solved," are specific issues related to the technology. The second category, and the one that is much harder to overcome, involves interpersonal issues among Extension educators, community partners and families. The third category involves interacting with Michigan State University's Institutional Review Board in a new, uncharted way.

The technology challenges were identified early on, and have been addressed as much as possible throughout the process. One of the first challenges was the need for families to have "immediate" results. Families wanted a comprehensive web presence, complete with all that is expected today in a quality website. The timeframe to complete such a web presence was not something that families could understand or easily accept, and has continued to be a challenge for long-term engagement. As with any other web user, if a family seeks information and cannot find it on the CMF website, they report that they are forced to go to another website. With the help of focus group input, the web presence has grown over the course of the project and includes many more components today. Improvement is still needed, however, and families continue to identify gaps.

One need identified by families was the ability to have immediate access to the survey results. Families expressed an interest in reading what others had experienced. This was a relatively easy challenge to overcome, and has proven to be a useful tool for all of the project partners. Now, after logging into the survey site, members have the option of seeing each survey's aggregated results. This is not only helpful to families, but also to community partners who use these data to inform programming priorities. 
The second set of challenges is interpersonal in nature. The project is comprised of a diverse range of partners, all coming to the project with their own needs. The biggest hurdle is helping everyone understand the cost-reward ratio of providing and accessing a new resource that is not yet fully developed. In fact, the development hinges on complete engagement, commitment, and action of all community members involved. The acts of engagement, commitment and action require a level of trust and vision for a pay-off that is distant, ambiguous, and uncertain. The strategy for addressing this challenge has been in capitalizing on the relationships that already exist, and the social capital inherent within them. Families are identified by Extension professionals who already have relationships established with them. Extension professionals are mentored by colleagues both in the field and on campus. The final bridge that continues to be nurtured is between Extension professionals in the field and the research community on campus.

The third set of challenges involves changes in the interactions with the University's Institutional Review Board (IRB). Researchers typically must obtain human subjects approval for all survey protocol before data are collected from participants. This can be a lengthy process in most instances, at times requiring weeks of negotiation. However, the nature of this research is community based and conducted mostly online. Specifically, input and active participation on the part of participants is crucial to the success of building an online community. We felt it was important that the online survey topics be participant-driven. In order to keep participants engaged in the process, it was important that the surveys be available on a specified and agreed upon timeline each month. To remedy this conflict of priorities, we kept in close contact during the approval process. The IRB originally wanted each of the monthly surveys to be submitted for approval prior to making them available on the website. However, feedback and lessons learned from participants in Phase I convinced the IRB to modify the process for the sake of the participants. Because the 
surveys were generated from the focus groups, the IRB approved our research such that we could craft the surveys without submitting each one for approval, with the parameters that there will be no controversial topics such as sex, drugs, and personal medical information.

Table 2. Project Summaries: Phases I, II, and III

\begin{tabular}{|c|c|c|}
\hline Phase I & Phase II & Phase III \\
\hline $\begin{array}{l}\text { Partners } \\
\text { - Families in selected } \\
\text { counties. } \\
\text { - County MSU } \\
\text { Extension educators. } \\
\text { - MSU faculty and } \\
\text { students. } \\
\text { - Community and state- } \\
\text { wide organizations. } \\
\text { Process - Focus groups: } \\
\text { - Built trust. } \\
\text { - Determined needs. } \\
\text { - Determined resources } \\
\text { for and barriers to } \\
\text { project participation. } \\
\text { - Developed topics for } \\
\text { online surveys. }\end{array}$ & $\begin{array}{l}\text { Family Resilience Study } \\
\text { - Selected counties re- } \\
\text { engaged families and } \\
\text { recruited additional } \\
\text { families } \\
\text { - Project expanded to } \\
11 \text { counties. } \\
\text { Quasi-experimental } \\
\text { design-families in } \\
\text { experimental group: } \\
\text { - Participated in focus } \\
\text { groups. } \\
\text { - Completed pre- and } \\
\text { post- tests. } \\
\text { - Complete monthly } \\
\text { online surveys. } \\
\text { - Participate on } \\
\text { discussion forums. } \\
\text { - Participate in } \\
\text { debriefing focus } \\
\text { groups. } \\
\text { - } \text { Challenges } \\
\text { Collaborative process: } \\
\text { of all partners. } \\
\text { networs. } \\
\text { relationships. }\end{array}$ & $\begin{array}{l}\text { Virtual Family Resource } \\
\text { Center } \\
\text { Website designed } \\
\text { according to families' } \\
\text { feedback: } \\
\text { - The Family Learning } \\
\text { Center } \\
\text { - The Pulse of } \\
\text { Michigan Families } \\
\text { - The Family Resource } \\
\text { Library } \\
\text { Challenges } \\
\text { - Maintaining } \\
\text { engagement with } \\
\text { families despite } \\
\text { technological } \\
\text { complications } \\
\text { - Providing instant } \\
\text { access to results while } \\
\text { maintaining } \\
\text { confidentiality. } \\
\text { Potential Implications: } \\
\text { - Insight gained } \\
\text { concerning family } \\
\text { resilience and the } \\
\text { development of social } \\
\text { capital. } \\
\text { Families and } \\
\text { communities become } \\
\text { producers and }\end{array}$ \\
\hline
\end{tabular}

Michigan Family Review, 11, 5-20, 2006 (C) Michigan Council on Family Relations 


\begin{tabular}{|c|c|c|}
\hline $\begin{array}{l}\text { Lessons Learned: } \\
\text { Families-- } \\
\text { - Valued having a voice } \\
\text { and interacting with } \\
\text { other families. } \\
\text { - Desired a more } \\
\text { interactive website } \\
\text { with instant access to } \\
\text { survey results. } \\
\text { - Desired opportunities } \\
\text { to interact with other } \\
\text { families and } \\
\text { university experts. }\end{array}$ & $\begin{array}{l}\text { Human subjects review } \\
\text { process: } \\
\text { - New ways of } \\
\text { negotiation with the } \\
\text { MSU Institutional } \\
\text { Review Board. } \\
\text { - Conveying the } \\
\text { importance of } \\
\text { participant-driven } \\
\text { research, while } \\
\text { maintaining ethical } \\
\text { integrity. }\end{array}$ & $\begin{array}{l}\text { consumers of } \\
\text { information. } \\
\text { - Stakeholders become } \\
\text { consumers of family- } \\
\text { based information. } \\
\text { - Policy analysis. } \\
\text { - Family needs } \\
\text { assessments in } \\
\text { counties. } \\
\text { - Reciprocal learning } \\
\text { process. } \\
\text { - University strengths } \\
\text { and resources } \\
\text { available at expanded } \\
\text { capacities. }\end{array}$ \\
\hline
\end{tabular}

\section{Implications}

\section{Research}

This has been a ground-up research process for which there was no precedent. Community based research offers a unique set of challenges and opportunities, and creating a virtual community has added an additional layer of challenge and opportunity. As researchers, it is incumbent upon us to keep Extension partners and participants engaged throughout a sometimes circuitous process, help them understand the constraints and value of a specific research protocol, to nurture an environment of trust, and to develop collaborative models that are sustainable.

Advances in technology and increasing foci on community based, critical research opens up new opportunities for interacting with Institutional Review Boards. It is important that researchers maintain communication with their IRB in order to inform them of the nature of research that is unique in design and participant led. 
Extension Educators and other Family Life Education Professionals

If digital divide issues can be adequately addressed, the CMF model can be an effective and innovative tool to reach new and nontraditional audiences. As documented by the Pew Internet and American Life Project, Internet use is changing rapidly and has increased even since the commencement of this project (Horrigan \& Murray, 2005). In an era of tight budgets and high energy costs, technological solutions can reduce the need for travel while reaching large audiences. The topics for information provided to families can be constituent generated and more timely and dynamic in nature than traditional modes. There also is potential for collaboration among multiple organizations and at the county and state levels. Extension professionals who became involved in this project did so despite heavy commitments to other initiatives. To sustain a process such as CMF, it must be embraced by central administrators as well as county staff and be incorporated into the culture. It is very likely that this will happen in the future as attitudes change, knowledge and comfort increase, and technology continues to evolve.

\section{Families}

Using the resilience framework, a system such as CMF could be a new resource for families. It will be perceived as a resource only if families are comfortable with its accessibility, ease of use, confidentiality and quality of information provided. In addition to providing information, an Internet system gives families a voice in the creation of information as well as providing feedback to both educators and policy makers, at multiple levels, in a non-politicized context.

\section{Conclusion}

This project is an evolutionary process in an era of rapid change in Internet access and use by families at all stages of the 
life course. It was directed toward answering questions related to the use of technology to support families and give voice to their needs and interests as they negotiate their daily lives. It is a unique collaborative among university researchers, Extension professionals and Michigan families, and the process and lessons learned have important implications for educators, researchers and policy makers.

\section{References}

Barrera, M., Glasgow, R. E., McKay, H. G., Boles, S. M., \& Fei, E. G. (2002). Do Internet-based support interventions change perceptions of social support?: An experimental trial of approaches for supporting diabetes self-management. American Journal of Community Psychology, 30, 637-654.

Campbell, M. K., Meier, A., Carr, C., Enga, Z., James, A. S., Reedy, J., et al. (2001). Health behavior changes after colon cancer: A comparison of findings from face-to-face and on-line focus groups. Family Community Health, 24, 88-103.

Fallows, D. (2005). How women and men use the Internet. Pew Internet and American Life Project. Retrieved February 28, 2006, from http://www.pewinternet.org.

Fox, S. (2005). Digital divisions. Pew Internet and American Life Project. Retrieved February 28, 2006, from http://www.pewinternet.org.

Horrigan, J. \& Murray, K. (2006). Rural broadband Internet use. Pew Internet and American Life Project. Retrieved February 28, 2006, from http://www.pewinternet.org.

McCubbin, H. I. \& Patterson, J. M. (1983). The family stress process: The double ABCX model of adjustment and 
adaptation. In H. I. McCubbin (Ed.), Social stress and the family (pp. 7-27). New York: Haworth Press.

Olson, D. H. (1993). Family continuity and change: A family lifecycle perspective. In T. Brubaker (Ed.), Family relations: Challenges for the future (pp. 17-40). Newbury Park, CA: Sage Publications.

Patterson, J. M. (2002). Integrating family resilience and family stress theory. Journal of Marriage and Family, 64, 349-360.

Smith, C. A. (1999). An essay for practitioners: Family life pathfinders on the new electronic frontier. Family Relations, 48, 31-34.

Spooner, T. (2003). Internet use by region in the United States. Pew Internet and American Life Project. Retrieved February 28, 2006, from www://pewinternet.org.

White, J. M., \& Klein, D. M. (2002). Family theories ( $2^{\text {nd }} \cdot$ ed.). Thousand Oaks, CA: Sage Publications. 